\title{
Experiences of social support among women presenting for obstetric fistula repair surgery in Tanzania
}

\author{
Alexis C Dennis' \\ Sarah MWilson ${ }^{1-3}$ \\ Mary V Mosha ${ }^{4}$ \\ Gileard G Masenga ${ }^{4}$ \\ Kathleen J Sikkema ${ }^{1,5,6}$ \\ Korrine E Terroso' \\ Melissa H Watt ${ }^{1}$ \\ 'Duke Global Health Institute, Duke \\ University, ${ }^{2}$ Department of Veterans \\ Affairs, Mid-Atlantic Mental Illness \\ Research, Education and Clinical \\ Center, ${ }^{3}$ Durham Veterans Affairs \\ Medical Center, Durham, NC, USA; \\ ${ }^{4}$ Kilimanjaro Christian Medical \\ Center, Moshi, Tanzania; ${ }^{5}$ Department \\ of Psychology and Neuroscience, \\ Duke University, Durham, NC, USA; \\ ${ }^{6}$ Department of Psychiatry and Mental \\ Health, University of Cape Town, \\ Cape Town, South Africa
}

This article was published in the following Dove Press journal:

International Journal of Women's Health

6 September 2016

Number of times this article has been viewed

Objective: An obstetric fistula is a childbirth injury resulting in uncontrollable leakage of urine and/or feces and can lead to physical and psychological challenges, including social isolation. Prior to and after fistula repair surgery, social support can help a woman to reintegrate into her community. The aim of this study was to preliminarily examine the experiences of social support among Tanzanian women presenting with obstetric fistula in the periods immediately preceding obstetric fistula repair surgery and following reintegration.

Patients and methods: The study used a mixed-methods design to analyze cross-sectional surveys $(\mathrm{n}=59)$ and in-depth interviews $(\mathrm{n}=20)$.

Results: Women reported widely varying levels of social support from family members and partners, with half of the sample reporting overall high levels of social support. For women experiencing lower levels of support, fistula often exacerbated existing problems in relationships, sometimes directly causing separation or divorce. Many women were assertive and resilient with regard to advocating for their fistula care and relationship needs.

Conclusion: Our data suggest that while some women endure negative social experiences following an obstetric fistula and require additional resources and services, many women report high levels of social support from family members and partners, which may be harnessed to improve the holistic care for patients.

Keywords: Tanzania, obstetric fistula, maternal morbidity, social support

\section{Introduction}

An obstetric fistula is a hole between the vagina and the bladder (vesicovaginal fistula $[\mathrm{VVF}]$ ) and/or rectum (rectovaginal fistula [RVF]), resulting in uncontrollable leakage of urine and/or feces. The condition occurs when the fetus cannot successfully pass through the birth canal during labor. ${ }^{1}$ Without medical intervention, the mother can remain in labor for days, while the fetal head compresses the soft tissues of the pelvis, eventually causing tissue necrosis and, usually, stillbirth. ${ }^{1,2}$ It is also possible for a woman to have an iatrogenic fistula, caused by surgical error during obstetric or gynecological surgery. ${ }^{3}$ Less than 1/1,000 women of reproductive age in low- and middle-income countries are living with an obstetric fistula, and the prevalence rises to $1.57 / 1,000$ women living in sub-Saharan Africa and South Asia. ${ }^{4}$ It is, however, important to note that only limited epidemiological data describing obstetric fistula exist due to the relative rarity of the condition and the fact that it usually affects women living in remote, resource-limited settings. ${ }^{5}$ In Tanzania, it is estimated that $\sim 46,000$ women are living with obstetric fistula. ${ }^{6}$

Surgical care is increasingly available for women with obstetric fistula. Since 2005, Tanzania has undertaken efforts to identify women living with fistula and refer
Correspondence: Melissa H Watt

Duke Global Health Institute, Duke

University, Box 90519, 310 Trent Drive,

Durham, NC 2770I, USA

$\mathrm{Tel}+19196136126$

Email melissa.watt@duke.edu
International Journal of Women's Health 2016:8 429-439

429 
them to free surgical repair. ${ }^{7}$ Yet, some Tanzanian women may live with obstetric fistula for decades before receiving any treatment. ${ }^{8}$ Without treatment, in addition to enduring a traumatic birth experience and losing a child, women may experience physical challenges, obstructed labor injury complex, ${ }^{2,9}$ and depression and other psychological impairments. ${ }^{10,11}$ The persistent leaking can magnify the difficulty of living with these physical and psychological problems and contribute to economic hardship, ${ }^{12}$ stigmatization by their community, ${ }^{8}$ and overall low quality of life. ${ }^{13}$ Women's experiences of isolation and abandonment by their families and husbands following an obstetric fistula have been well documented. ${ }^{2,13,14}$ Tanzanian women presenting with fistula surgery have reported significantly less social support when compared to other gynecology outpatients, and a significant proportion of women end up divorced or separated from their partners. ${ }^{2,11,12,15}$ Severed interpersonal and intimate relationships have been described as a typical experience of fistula patients.

Obstetric fistula repair surgery has been demonstrated to positively impact a woman's life through improvements in her physical condition and in her interpersonal relationships. ${ }^{16}$ Although some women do not fully recover from the first surgical repair of their fistula and will continue to experience symptoms or will need additional surgery, many women do benefit from surgical repair. ${ }^{17}$ Both prior to fistula surgery and during the surgical treatment and recovery periods, social support can help a woman to heal emotionally and to reintegrate into her community. This study aims to enrich our understanding of the experiences of social support in women with obstetric fistula by using a mixed methods design to preliminarily examine the social support of women presenting with obstetric fistula in the period immediately preceding obstetric fistula repair surgery as well as following reintegration.

\section{Patients and methods}

\section{Study design}

We conducted a mixed-methods analysis of survey data and in-depth interviews with Tanzanian women undergoing obstetric fistula repair surgery. The data were collected as part of the pilot study of a mental health intervention for obstetric fistula patients. ${ }^{18}$ The Duke University, Kilimanjaro Christian Medical Centre (KCMC), and Tanzania National Institute for Medical Research ethical review boards approved all study procedures.

\section{Study setting}

The study took place at KCMC located in Moshi, Tanzania. KCMC's Department of Obstetrics and Gynaecology provides free surgical repair services for obstetric fistula to $\sim 40-50$ patients annually and has a dedicated 12-bed fistula ward. The patients admitted to the fistula ward typically undergo reparative surgery within 1 week of admittance and remain hospitalized after $\sim 4$ weeks of surgery. Upon discharge, the patients receive instructions to drink adequate fluid, to abstain from sexual activity, and to avoid strenuous activities for 3-6 months postrepair. The patients also receive verbal instruction in conducting pelvic floor exercises and are advised to continue these exercises regularly.

\section{Recruitment and study population}

The study participants were recruited from the KCMC fistula ward. During the recruitment period, a nurse on the fistula ward identified potential study participants, and the study coordinator (a research staff member who did not provide clinical care) screened patients consecutively for eligibility until a sample of 59 was reached. Women were eligible to participate if they were at least 18 years old, spoke proficient Swahili, could provide informed consent, and were currently admitted for surgical treatment of an obstetric fistula (caused by either obstructed labor or cesarean section). All participants provided written informed consent. Illiterate participants indicated their consent on the consent form using their thumbprint. Women in need of either a first operation or reoperation were eligible for participation.

The total sample included quantitative data from 59 patients and qualitative data from a subset of 20 patients. Demographic features of all the study participants are summarized in Table 1, and demographic features of the subset of qualitative participants are summarized in Table 2.

\section{Quantitative procedures and measures}

All study measures were translated by a native Swahili speaker, as Swahili is the predominant language in Tanzania. Following initial translation, the study coordinator, who spoke Swahili as the first language, reviewed the translated measures, and irregularities were discussed and retranslated. The measures were then back translated into English, and irregularities were again discussed and retranslated. A visual analog of Likert scale response choices, comprising circles of increasing size to represent the strength of response, was used to facilitate more accurate self-report. ${ }^{19}$ The participants were able to verbally respond or point to the circle that indicated a response.

The study coordinator orally administered the survey in Swahili within 4 days of a patient's admission to the fistula ward and prior to her surgery. Surveys were administered in a private room and lasted $\sim 60$ minutes. The patients were 
Table I Sample characteristics

\begin{tabular}{|c|c|c|}
\hline & n (59) & $\%$ \\
\hline \multicolumn{3}{|l|}{ Age (years) } \\
\hline $18-24$ & 12 & 20.3 \\
\hline $25-34$ & 10 & 16.9 \\
\hline $35-44$ & 13 & 22.0 \\
\hline $45-60$ & 15 & 25.4 \\
\hline $61-80$ & 9 & 15.3 \\
\hline \multicolumn{3}{|l|}{ Education level } \\
\hline Completed standard $7^{\mathrm{a}}$ or higher & 30 & 50.8 \\
\hline \multicolumn{3}{|l|}{ Currently working to earn income } \\
\hline Yes & 37 & 62.7 \\
\hline \multicolumn{3}{|l|}{ Religion } \\
\hline Christian & 23 & 39.0 \\
\hline Muslim & 35 & 59.3 \\
\hline Not religious & 1 & 1.7 \\
\hline \multicolumn{3}{|l|}{ Average number of other adults } \\
\hline \multicolumn{3}{|l|}{ in household } \\
\hline Mean (SD) & $1.86(1.805)$ & \\
\hline Range & $0-11$ & \\
\hline \multicolumn{3}{|l|}{ Living children } \\
\hline Yes & 39 & 66.1 \\
\hline \multicolumn{3}{|l|}{ Children delivered prior } \\
\hline \multicolumn{3}{|l|}{ to developing fistula } \\
\hline Mean (SD) & $\mathrm{I} .76(2.22)$ & \\
\hline Range & $0-9$ & \\
\hline \multicolumn{3}{|l|}{ Relationship status $^{b}$} \\
\hline Married - nonpolygamous & 17 & 25.4 \\
\hline Married - polygamous & 12 & 20.3 \\
\hline Separated/divorced & 16 & 30.5 \\
\hline Widowed & 6 & 10.2 \\
\hline Never married & 8 & 13.6 \\
\hline \multicolumn{3}{|l|}{ Currently living with husband } \\
\hline \multicolumn{3}{|l|}{ or partner } \\
\hline Yes & 29 & 49.2 \\
\hline \multicolumn{3}{|l|}{ Separated/divorced due to fistula } \\
\hline Yes & 9 & 15.3 \\
\hline \multicolumn{3}{|l|}{ Months living with fistula ${ }^{b}$} \\
\hline Mean (SD) & I $70.95(\mid 78.45)$ & \\
\hline Range & $0-674$ & \\
\hline \multicolumn{3}{|l|}{ Fistula type } \\
\hline Leaking urine (VVF) & 53 & 89.8 \\
\hline Leaking stool (RVF) & 2 & 3.4 \\
\hline Leaking urine and stool (VVF/RVF) & 4 & 6.8 \\
\hline \multicolumn{3}{|l|}{ Number of previous surgeries ${ }^{b}$} \\
\hline 0 & 44 & 77.2 \\
\hline 1 & 8 & 13.6 \\
\hline$\geq 2$ & 5 & 9.2 \\
\hline
\end{tabular}

Notes: ${ }^{\text {SStandard }} 7$ refers to the last year of primary school before secondary school; ' Missing data; $\mathrm{n}=57$.

Abbreviations: VVF, vesicovaginal fistula; RVF, rectovaginal fistula; SD, standard deviation.

compensated with a package of sanitary pads and a bag of toiletries worth $\sim$ US $\$ 5$.

\section{Demographics and obstetric history}

The patients reported demographic information (age, relationship status, religion, current employment, education, number of other adults in the household) and information about their obstetric history (months living with obstetric fistula, fistula type, any previous unsuccessful fistula repair surgery, whether they had living children, number of children delivered prior to developing fistula).

\section{Perceived social support}

To examine the social support experiences of women presenting with obstetric fistula in the period immediately preceding fistula repair surgery, we used the RAND Corporation's Medical Outcomes Study (MOS) Social Support Survey. The MOS is a 19-item measure of current perceived social support ${ }^{20}$ and has previously been used empirically in obstetrics and gynecology patients in South Africa. ${ }^{21}$ The participants were asked to endorse items related to how often they receive emotional/informational support (eight items), tangible support (four items), affectionate support (three items), and positive social interaction (three items). The response options were on a 5 -point Likert scale $(0=$ none to $4=$ all of the time). A mean score ( $0-4)$ was calculated across the 19 items, with high reliability $(\alpha=0.94)$. For descriptive purposes, we also transformed the scale into a total score ranging from 0 to $100{ }^{20}$

\section{Emotional and physical abuse by an intimate partner} Emotional and physical abuse experiences were measured using two dichotomous items adapted from the Conflict Tactics Scale, ${ }^{22}$ which has previously been used empirically with obstetrics and gynecology patients in Tanzania. ${ }^{23}$ The participants were asked if a partner or spouse had ever insulted them (yes/no) or hurt them physically (yes/no).

\section{Incontinence score}

Urinary incontinence scores were calculated for patients reporting a VVF, and fecal incontinence scores were calculated for patients reporting an RVF. The Medical, Epidemiologic and Social Aspects of Aging questionnaire is a nine-item measure that assesses the frequency of leaking urine during daily activities on a 4-point Likert scale $(0=$ never to $3=$ often $){ }^{24}$ We adapted the measure by adding four items to assess frequency of leaking urine when sitting, lying down, sleeping, or walking. The items were summed to yield a continuous urinary incontinence score (0-39). The experience of fecal incontinence was measured with a previously validated measure that included four items, also on a 4-point Likert scale $(0=$ never to $3=\mathrm{often}) .{ }^{25}$ The fecal incontinence items were averaged to yield a continuous fecal incontinence score (0-3).

\section{Intention to talk about fistula}

The research team developed a four-item measure to assess participants' intentions to discuss their fistula with a husband/ 
Table 2 Demographic characteristics of qualitative subsample

\begin{tabular}{|c|c|c|c|c|c|c|c|c|c|c|}
\hline Participant & $\begin{array}{l}\text { Fistula } \\
\text { type }\end{array}$ & $\begin{array}{l}\text { Months } \\
\text { living with } \\
\text { fistula }\end{array}$ & $\begin{array}{l}\text { Age } \\
\text { (years) }\end{array}$ & $\begin{array}{l}\text { Completed } \\
\text { standard } 7^{a} \\
\text { or higher }\end{array}$ & $\begin{array}{l}\text { Working to } \\
\text { earn income } \\
\text { prior to } \\
\text { surgery }\end{array}$ & Religion & $\begin{array}{l}\text { Number } \\
\text { of living } \\
\text { children }\end{array}$ & $\begin{array}{l}\text { Number of } \\
\text { other adults } \\
\text { in household } \\
\text { at follow-up }\end{array}$ & $\begin{array}{l}\text { Relationship status } \\
\text { at follow-up }\end{array}$ & $\begin{array}{l}\text { Living with } \\
\text { husband or } \\
\text { partner at } \\
\text { follow-up }\end{array}$ \\
\hline 01 & VVF & 173 & 40 & No & No & Muslim & 0 & 3 & Married & Yes \\
\hline 02 & VVF & 168 & 46 & Yes & Yes & Muslim & 5 & 4 & Married & Yes \\
\hline 03 & VVF & 10 & 44 & No & Yes & Muslim & 2 & 1 & Married & Yes \\
\hline 04 & VVF & 14 & 26 & No & Yes & Muslim & 2 & 4 & Separated/divorced & No \\
\hline 05 & VVF & 127 & 35 & Yes & Yes & Christian & 3 & 2 & Married & Yes \\
\hline 06 & VVF & 1 & 30 & No & No & Muslim & 0 & 1 & Married & Yes \\
\hline 07 & VVF & 229 & 50 & Yes & No & Muslim & 2 & 4 & Married & Yes \\
\hline 08 & VVF & 409 & 65 & No & Yes & Muslim & 6 & 7 & Married - polygamous & Yes \\
\hline 09 & $\begin{array}{l}\text { VVF and } \\
\text { RVF }\end{array}$ & 0 & 22 & Yes & Yes & Muslim & 0 & 2 & Never married & No \\
\hline 10 & VVF & 15 & 24 & Yes & No & Christian & 2 & 2 & Never married & No \\
\hline II & VVF & 387 & 53 & No & Yes & Muslim & 0 & 0 & Separated/divorced & No \\
\hline 12 & VVF & 183 & 60 & No & No & Muslim & 8 & 2 & Married - polygamous & Yes \\
\hline 13 & VVF & 232 & 39 & No & Yes & Christian & I & I & Married & Yes \\
\hline 14 & VVF & 27 & 23 & Yes & No & Muslim & 4 & 5 & Married & No \\
\hline 15 & RVF & 208 & 54 & Yes & Yes & Christian & 2 & 3 & Widowed & - \\
\hline 16 & VVF & 209 & 31 & Yes & Yes & Muslim & 2 & 2 & Separated/divorced & No \\
\hline 17 & VVF & 5 & 26 & Yes & No & Christian & I & 1 & Married & Yes \\
\hline 18 & VVF & 9 & 36 & Yes & No & Christian & 0 & 0 & Separated/divorced & No \\
\hline 19 & VVF & 13 & 35 & Yes & Yes & Christian & I & 2 & Married & Yes \\
\hline 20 & $\begin{array}{l}\text { VVF and } \\
\text { RVF }\end{array}$ & 327 & 42 & No & Yes & Muslim & 0 & 1 & Separated/divorced & No \\
\hline
\end{tabular}

Note: a Standard 7 refers to the last year of primary school before secondary school.

Abbreviations: VVF, vesicovaginal fistula; RVF, rectovaginal fistula.

partner, family member, close friend, or community member in the next 3 months. A dichotomous measure was created by assigning " 1 " if participants indicated that they intended to discuss their fistula in the future.

\section{Depression}

The Center for Epidemiologic Studies Depression Scale ${ }^{26}$ was used to assess depressive symptoms in the past week on a 4-point Likert scale $(0=$ rarely to $3=$ most or all of the time). The Center for Epidemiologic Studies Depression Scale has previously been validated in a South African patient population $^{27}$ and used empirically to measure depressive symptoms in Tanzanian obstetric fistula patients. ${ }^{11}$ The measure yielded a continuous depression severity score (0-60) with moderately high reliability $(\alpha=0.71)$.

\section{Self-esteem}

The Rosenberg Self-Esteem Scale is a ten-item scale used to measure global self-worth by assessing both positive and negative feelings about the self on a 4-point Likert scale $(0=$ strongly disagree to $3=$ strongly agree $) .{ }^{28}$ This measure has been previously used with an emerging adult population in Tanzania, ${ }^{29}$ and past research has also shown the applicability of the self-esteem construct to obstetric fistula patients. ${ }^{30}$ The items were slightly modified for use with a fistula population, as done previously. ${ }^{31}$ This measure yielded a continuous scale (0-30) with moderately high reliability $(\alpha=0.76)$.

\section{Qualitative procedures}

All women who returned for a follow-up appointment after $\sim 3$ months of discharge were asked if they would like to participate in an in-depth interview until a target subsample of 20 was reached. (Some women declined to participate.) Women from the intervention and control conditions of the larger study completed an in-depth interview. Interviews were conducted in Swahili by a research staff member. Interviews lasting $\sim 30$ minutes took place in a private room in the study clinic. The interviewer followed a semistructured guide that included open-ended probes related to the participant's experience returning home to her community and the social support she received. The participants were compensated with 20,000 shillings ( $\sim$ US\$9) and reimbursement of travel expenses.

\section{Analysis}

This article utilized a mixed-methods approach, a method designed to integrate quantitative and qualitative techniques into the interpretation of data to offer a multidimensional exploration of the issue under study. ${ }^{32}$ This approach enabled 
us to examine our quantitative and qualitative data concurrently and iteratively to glean depth to our understanding of the social support experiences of women presenting with obstetric fistula.

\section{Statistical analysis}

First, descriptive statistics were generated to characterize the demographics, obstetric histories, and social support patterns (mean values were used for normally distributed data, whereas median values were used for skewed data and proportions for categorical data). Since quantitative data were exploratory in nature, we opted to use a hypothesisgenerating approach rather than formal hypothesis testing. In order to explore potential associations with social support, we calculated polychoric correlation coefficients and 95\% confidence intervals (CIs) for the association between social support and each key variable (ie, demographics, fistularelated factors, and mental health indicators). All statistics were generated using SAS Version 9.3.

\section{Qualitative analysis}

The in-depth interviews were audio recorded, transcribed, and translated into English. Data analysis was inductive and iterative. ${ }^{33}$ Each transcript was read to identify main themes. Narrative memos summarizing the content of each transcript were then drafted to organize content into these main themes and to begin extracting meaning from the data. The narrative memos were coded using qualitative analytical software NVivo 10. Analytical memos were subsequently drafted from the code reports, which facilitated systematic identification of emergent themes in the data and enhanced understanding of relationships between themes identified during coding. ${ }^{34}$ Analytical memos were shared with other investigators, who provided input to ensure that key details from the original transcripts were accurately reflected. Relevant quotations were retained in both narrative and analytical memos to capture the voices of participants.

Throughout the analysis process, steps were taken to enhance study rigor and trustworthiness of findings. ${ }^{35}$ The research team discussed emergent ideas throughout the coding and analysis process; engaging researchers with diverse training and experience with the study population facilitated the reduction of bias and enhanced the credibility of the findings. ${ }^{36}$ To enhance the dependability and confirmability of the results, the first author kept an audit trail of analysis activities, emergent themes, and analytical memos to ensure consistency in analytical processes and techniques across time. ${ }^{37}$

\section{Results Quantitative findings}

The participants were on average 40.9 years $(\mathrm{SD}=16.4$, range 18-80 years), and they had been living with an obstetric fistula for 14.0 years ( $\mathrm{SD}=14.7$, range $0-56$ years). The majority of the sample had VVF, and among them, four women had both VVF and RVF (Table 1). Among those with VVF, the median incontinence severity score was 35 out of a possible 39 points (interquartile range 17-39). Among the six patients with RVF, the median incontinence score was 1.5 out of a possible 3 points (interquartile range 0.6-1.7). Approximately three-quarters of the participants were receiving reparative surgery for the first time. Less than half of the sample (42.4\%) developed the fistula during the course of their first delivery; the majority had a previous birth before the fistula occurrence. For $89.7 \%$ of the sample, the fistula labor resulted in a stillbirth. Half of the participants $(50.0 \%)$ self-identified as currently married or living with a husband or partner. Fifteen participants (28.8\%) reported that they were separated or divorced, of whom seven noted that their separation/divorce was a direct result of their obstetric fistula.

Regarding social support, the participants generally endorsed high levels of support. On each individual item in the measure, more than two-thirds of the sample selected "most of the time" or "all of the time". The distribution of this scale was heavily negatively skewed (skewness =-1.15), with $49.2 \%$ of participants endorsing the maximum social support score $($ median $=98.68$, interquartile range 60.53-100.0). Regarding subscales of social support, the median values for emotional support, tangible support, positive social interaction, and affectionate support were each 100 (interquartile ranges 53.1-100.0, 75.0-100.0, 41.7-100.0, and 75.0-100.0, respectively), with women reporting more variability in their experiences of emotional support and positive social interaction. Three variables were significantly correlated with social support (Table 3). Depression was inversely correlated with social support ( $\rho=-0.39$, CI: $-0.63,-0.15)$, such that individuals with higher levels of social support reported lower levels of depression. Self-esteem was positively correlated with social support $(\rho=0.30, \mathrm{CI}: 0.03,0.56)$, meaning that individuals with higher levels of social support reported higher levels of self-esteem. Intention to talk about fistula ( $\rho=0.62$, CI: $0.29,0.96)$ was also positively correlated with social support. Since this measure was dichotomous, this polychoric correlation coefficient can be interpreted such that individuals who planned to discuss fistula in the next 3 months with family or friends had higher levels of social 
Table 3 Correlations with social support $(n=59)$

\begin{tabular}{|c|c|c|}
\hline & $\begin{array}{l}\text { Polychoric } \\
\text { correlation } \\
(\rho) \text { with social } \\
\text { support }\end{array}$ & $95 \% \mathrm{Cl}$ \\
\hline Age & -0.24 & $(-0.51,0.02)$ \\
\hline Currently married & -0.23 & $(-0.57,0.11)$ \\
\hline Completed standard $7^{\mathrm{a}}$ or higher & 0.24 & $(-0.10,0.57)$ \\
\hline Currently earning income & 0.20 & $(-0.15,0.55)$ \\
\hline Presence of living children & 0.24 & $(-0.11,0.58)$ \\
\hline Presence of adults in the household & 0.12 & $(-0.17,0.41)$ \\
\hline $\begin{array}{l}\text { Has experienced emotional abuse } \\
\text { from partner }\end{array}$ & 0.08 & $(-0.32,0.49)$ \\
\hline $\begin{array}{l}\text { Has experienced physical abuse } \\
\text { from partner }\end{array}$ & 0.17 & $(-0.25,0.58)$ \\
\hline Urinary incontinence score ${ }^{\mathrm{b}}$ & 0.24 & $(-0.05,0.53)$ \\
\hline Months lived with fistula & -0.04 & $(-0.33,0.25)$ \\
\hline $\begin{array}{l}\text { Plans to discuss fistula during } \\
\text { reintegration }\end{array}$ & 0.62 & $(0.29,0.96)$ \\
\hline Depression score & -0.39 & $(-0.63,-0.15)$ \\
\hline Self-esteem score & 0.30 & $(0.03,0.56)$ \\
\hline
\end{tabular}

support. Other variables with medium effect sizes that did not reach significance included age, education level, marital status, presence of living children in the household, whether the participant was currently earning income, and urinary incontinence score.

\section{Qualitative findings}

Qualitative interviews conducted after 3 months of discharge revealed the extent to which women received emotional, tangible, and financial support from partners and family members while living with fistula and during the reintegration period.

\section{Experiences of support from partners}

About half of the participants described their partners as supportive caregivers, who provided sympathy and encouragement before fistula repair, during treatment, and throughout recovery. One woman recalled her husband's initiative immediately after her fistula developed:

I am very much proud of my husband that he did not neglect me. We were together on every step. [...] My husband called a doctor who directed us to come to KCMC for further examination. Although I was very scared with such a problem, I can say [my] husband tried very hard and quickly to make sure that the problem is tackled. [19]
Another woman recounted her husband's desire to accompany her to her follow-up appointment:

He is so happy that I am no longer leaking as well as walking properly. That is why he came with me, just to know the progress and to listen [to] what the doctor will say. I think he thanks God very much for such a difference [in my prognosis] and especially for the complete cure. [06]

The women said that their partners also supported them by helping them adhere to their medical recommendations, particularly the recommendation to abstain from sex for 3 months postsurgery. Some women returned home to their partners but completely abstained from intercourse, as described by participant 02 :

He said, "no problem my wife ... we can sleep [in] the same bed" and he never touched me asking for sex.

Other women and their partners decided the best way to avoid sex was for her to recover at the home of a relative or, among polygamous couples, for the husband to stay with another wife. Supportive partners seemed to willingly sacrifice their short-term desires for their partner's long-term healing, as described by participant 17 :

He could see me with grief or sadness concerning my leaking. He knows that the [abstinence] recommendation given has a limitation, so nothing to worry about.

Women seemed to facilitate sex negotiations with their partners, as opposed to passively reacting to their partner's wishes.

Additionally, a few women described receiving tangible or financial support from their partners before or after surgery. One woman [07] described how her husband helped her clean her clothes prior to surgery, and another [14] said that her husband brought her "whatever she needed" during her recovery. One participant [17] believed that her husband would provide her with capital to restart her business once she fully recovered.

\section{Experiences with nonsupportive partners}

About half of the samples described having strained relationships with their partners and reported challenges in social support. Reasons for strained relationships varied. Some women experienced discouragement from attending follow-up visits, such as one woman who related her husband's obstinacy to prior failed fistula surgeries:

He did not like me going to Moshi for treatment follow-up.

He counted all areas where I had gone before with no 
success. Now he said, "I don't want you to go again to Moshi. You just leave it. You have gone to Dar-es-Salaam and again in Tanga coming back with the same problem. You have gone to Moshi and now you want to go again, what is so special to go at this time?" [12]

This woman, however, seemed to advocate for herself, and returned for her follow-up appointment without her husband's blessing:

So I prepared myself [to] go [to KCMC] without [my husband] knowing that I had traveled to Moshi the same day when he refused me to come. [...] Nobody will think of your body. You have to take care of yourself. He wants me to go to the field to cultivate. ... I had to give myself permission to come.

Immediately following fistula repair, a few women opted to stay elsewhere against their partners' wishes because they doubted their partner would prioritize their healing. Some took additional measures to ensure proper healing by covertly extending the number of months for abstinence beyond the hospital recommendations, as explained by participant 03 :

I shall tell him that I am forbidden [to have sex] for ten months. I push the dates forward alone. So that I am completely ok.

For many participants, the decision to take additional measures seemed to stem from a belief that men are incapable of resisting sex.

Some women described their primary relationship prior to fistula development as casual or problem ridden. In these cases, the fistula often exacerbated preexisting challenges. For example, a few women were impregnated by casual partners: two were abandoned during their pregnancies and the third [10] reported that "he ran away after finding that I got the leaking problem. I don't know where he is." Other women who thought their husbands were unreliable prior to developing their fistulas reported that their husbands' negative behaviors intensified after they developed their fistula, as exemplified by participant 16 :

[Before the fistula he] used to support me but not always. He was not [financially] stable. He did not stick to one person so I found that it was dangerous to me. After finding that I am leaking he started to go here and there so I decided to move away from him.

Of the six separated or divorced women in our qualitative sample, three attributed the dissolution of their relationships directly to the fistula, while others described longer term recurrent issues that led to the separation.

The women in our sample who received limited support from their partners seemed proactive in their decision-making about the future of their relationships. Although the actions of unsupportive partners seemed to hurt women emotionally, these participants seemed to prefer to end the relationship than to return to their partner. The following quotes exemplified participants' sentiments:

[My parents] asked me if your husband comes and wants to take you back to your home what will you say? I told them that I will never go back there. He never paid any [bridewealth] so enough is enough. [04]

I felt very bad because he disappeared and he did not want to come to me after I told him that I am pregnant, so why should he come to ask for me? He did not care [for me] before so I don't want him anymore. My love for him is over. [09]

No, no he cannot do so [visit me in the hospital]. I will fight him. [Laughing] I cannot tolerate to see someone who ran away from me after identifying that I got this problem, I don't want him even to pass in front of my eyes. [10].

Women with unsupportive partners seemed to view their fistula repair and recovery experiences as evidence of their own strength, and a few expressed a desire to live independently of men once they fully recovered, as described by one woman:

Really I don't want to see him again as being a husband. I have changed my mind now. I have now learned how I can manage... I will start to be independent, as I will set my goals. [04]

Even one participant, whose partner still loved her, stated:

Yes he is still [in love with me] but on my side I don't want to live with him. That [pregnancy] was just an accident. I want to live independently. I want to see how my life will be. [13]

\section{Experiences of support from families}

Almost all the women in our sample, whether married or not, belonged to larger family units and indicated receipt of some form of emotional, tangible, or financial support from their relatives, which included parents, siblings, in-laws, children, and grandchildren. 


\section{Emotional support}

Most women reported receiving a warm reception and sympathy upon returning home. They recalled how family members who lived far away visited them, welcoming them with songs, gifts, and food, as illustrated by participant 01 : "I was welcomed home happily. [My sisters] came to shore to see me $[. .$.$] and gave me good company." A few women,$ who were embarrassed by their condition and anxious about returning home, were pleasantly surprised by the support of their family; one woman [09] recalled, "I felt ashamed because I thought [my brothers] would laugh at me ... but they showed sympathy and said very sorry." Only one woman [11], whose surgery was unsuccessful, described her relatives as unwelcoming upon her return: "Others dared to say, 'it is your concern. You thought that going to Moshi will help. See now, things are very different and worse."'

Family members also provided emotional support for a few women who were navigating strained relationships with their partners. Women described relatives who advocated for them with their unsupportive partners prior to receiving treatment and continued offering support as they contemplated leaving their partners post-surgery. The following quotes illustrate the experiences of these participants:

I can say my sister does not want me to go back to my husband. [She said], "You have to stay here, we love you, we will help you, your children are healthy, they eat well, and you don't have to go." [04]

My husband did not want me to come [to KCMC] for follow up, but my children told me "mum it is for your own well-being, so if you do not go it is up to you." So in fact I decided to come for my follow up. I can say I am proud of having them, as they take concern about my health. [12]

\section{Financial and tangible support}

Almost all women reported receiving financial or tangible support from family members. Over half of the women received financial support that aided them in their shortterm recovery and their long-term stability. For example, the women described relatives who pooled their resources to send them back to KCMC for follow-up appointments or to help them access medical care if they fell ill during recovery, as one woman described:

Those who came to see me hired a car that sent me to (the) district hospital (for additional treatment) and they paid 70,000 [Shillings] to reach the hospital. [08]

Other women reported that relatives promised to loan them capital to start a business or help them find a job.
Both before and after surgery, family members provided women with assistance with food, shelter, household chores, and provision of care for the patients and their children. These women described the support they received from family members both before and after surgery:

In fact my mother played a big role. Buying me pads and also [...] she help[ed] me with washing my clothes, giving me a bath at the time in the hospital. Really I can say my mother was and is there for everything for me. She t[ook] out the mattress to dry when it [was] wet. She comb[ed] my hair, appl[ied] oil to my skin. I really appreciate what my mother did for me. [10]

In fact [I have done nothing] as they (the family) cook, I just sit down and eat. Yes only eating as they do all activities, cooking, washing, and everything that need to be done they do it. [They] really love me. They can recall for how long I have been suffering. [08]

\section{Discussion}

This mixed-methods study used cross-sectional surveys and in-depth interviews to examine the social support experiences of women undergoing obstetric fistula repair surgery.

This study challenges previous representations of obstetric fistula patients by demonstrating that while some women experience isolation and negative social experiences following an obstetric fistula, many other women report high levels of tangible, financial, and emotional support from family members and partners. There were a number of ways in which this sample differed from more prototypical samples of obstetric fistula patients ${ }^{2}$ : the patients had relatively low rates of divorce, were of older age, and had lived with a fistula for an extended time. Additionally, many of the women in this sample had given birth to at least one child prior to developing an obstetric fistula, which might make them more integrated into their families and communities than women who were childless. These characteristics of the sample must be taken into account when interpreting qualitative and quantitative findings. Qualitative interviews with the patients reflected the salience of family relationships and revealed women's assertiveness in their fistula care and relationships. Overall, the findings underscored that women who received surgical intervention for obstetric fistula in Tanzania were diverse in their levels of social support, and many women exhibited agency and resilience in the period following surgery.

Our quantitative data demonstrated that the majority of women in this sample endorsed high rates of social support 
at the time they presented for fistula repair. This finding was somewhat unexpected, given past empirical findings linking obstetric fistula with deficits in social support. ${ }^{2,11,15}$ Despite overall high levels of social support, variability in the social support measure was also high. The quartile of the sample with the lowest social support all had scores that reflected great deficits in social support. Additionally, $13 \%$ of our sample reported that their fistula caused separation or divorce from their spouse, and moreover, qualitative data revealed that marital distress may be present for women who received repeated surgeries without a successful outcome. This supports our interpretation that following the development of obstetric fistula, there is variability in social consequences; some may experience a mobilization of social support, while others may experience no change or a decrease in support. As such, additional services may be needed for women with chronically low social support or sudden changes in support, and practitioners could also harness the high levels of social support received by some patients to improve holistic care overall.

Our findings indicated that social support was correlated with lower depression scores, higher self-esteem scores, and planning to discuss fistula with others. A similar association between depression and social support was previously documented in obstetric fistula patients in Kenya. ${ }^{38}$ While it is difficult to ascertain the directionality of this relationship, it suggests that degraded social support may have considerable effects on mood and self-image. It is also notable that high social support was associated with having a plan to discuss obstetric fistula in the future. This suggests that women who feel supported by their family and/or community may experience less stigma regarding fistula and an increased willingness to acknowledge this childbirth injury. For women receiving surgery for obstetric fistula, intervening to improve both social functioning and mental health may be mutually beneficial.

Themes identified in the in-depth interviews confirmed the survey findings. Similar to the quantitative results, the qualitative results suggested that women received tangible, financial, and emotional support from individuals in their social circle. Thematic content clarified that women did not exclusively rely upon partners for support, but rather drew upon support from a variety of familial relationships, and future research should explore the roles played by specific family members, including living mothers, in the provision of social support. To help navigate intimate relationships, the women in this sample often relied on other family members for help. For women who described problems in their intimate relationships, these problems often predated the development of fistula. About half of our quantitative and qualitative samples indicated that their obstetric fistula was a direct cause of a divorce or separation. However, in many cases, the development of fistula and subsequent leaking represented an exacerbation of existing problems in the relationship, rather than a novel cause of the problems.

The qualitative data also suggested that women were often empowered to support themselves through assertiveness and self-advocacy. These experiences contradict existing narratives that allude to women with obstetric fistula as largely disenfranchised and voiceless. ${ }^{12,13}$ In contrast, our data suggest that many women with fistula have the potential to advocate for themselves to receive treatment, and they can be proactive in following through with physician recommendations. Furthermore, when the women in this sample had problematic spousal relationships, many of them demonstrated their empowerment by making informed choices about whether or not to leave these situations. Perhaps, the experience of undergoing surgery empowered women to advocate for their needs and desires during recovery. However, similar to our quantitative findings, there was evidence of diversity in social circumstances and the level of empowerment. In short, women did not universally tend to describe themselves as powerless or solitary, but instead exhibited varying levels of proactivity and resilience.

This study has limitations worth noting. The experiences reported here may not reflect the social support experiences of women who never reach fistula care. Additionally, the findings may not reflect the experiences of women living with obstetric fistula in other countries where cultural contexts and gender norms may differ. Although there are significant gender disparities in Tanzania based upon education and literacy, these disparities are not as pronounced as in other countries where obstetric fistula is prevalent. ${ }^{39}$ For both qualitative and quantitative methodologies, the participants may have been influenced by a social desirability bias, which could have limited their discussions of lapses in social support. Scale validation and assessment of the cultural salience of our questionnaire were beyond the scope of this study and thereby may have limited the validity of our quantitative findings. Owing to the sample size, the study may have limited statistical power to detect group differences based on social support. Additionally, research participants reported very high levels of social support, which limited the variability in the sample. This possible ceiling effect may have made it more difficult to detect correlations with social support. Regarding qualitative data limitations, the participants were a subset of women who returned for their 3-month follow-up 
visit. Since this group of women may have been especially pleased with their surgical outcome or able to travel due to a high level of empowerment, they may be a biased subset of the larger quantitative sample. Despite these limitations, the findings provide health care providers and researchers with rich information that can inform direct clinical care of obstetric fistula patients, future research in this population, and the underlying narratives that are used to describe these patients.

\section{Conclusion}

This sample of obstetric fistula patients in Tanzania reported widely varying levels of social support from their partners and both immediate and extended family members. Both quantitative and qualitative analyses indicated that although there were some prominent lapses in support and empowerment, most of these women were generally supported and demonstrated remarkable resilience. In addition to sometimes being a direct cause of social isolation, obstetric fistula often exacerbated existing problems in relationships. In contrast to a depiction of fistula patients as subjugated and powerless, however, qualitative interviews highlighted many cases of assertiveness in personal relationships.

\section{Acknowledgments}

We would like to thank Pili Nyindo for her contributions to this study. This project was supported by the Eunice Kennedy Shriver National Institute of Child Health and Human Development, grant R21 HD073681 (PI, Watt). Manuscript preparation was in part supported by the U.S. Department of Veterans Affairs Office of Academic Affiliations, Advanced Fellowship Program in Mental Illness Research and Treatment. The views expressed in this article are those of the authors and do not represent the views of the Department of Veteran Affairs or the United States government.

\section{Disclosure}

The authors report no conflicts of interest in this work.

\section{References}

1. Semere L, Nour NM. Obstetric fistula: living with incontinence and shame. Rev Obstet Gynecol. 2008;1(4):193.

2. Ahmed S, Holtz S. Social and economic consequences of obstetric fistula: life changed forever? Int J Gynecol Obstet. 2007;99(suppl 1): S10-S15.

3. Raassen TJ, Ngongo CJ, Mahendeka MM. Iatrogenic genitourinary fistula: an 18-year retrospective review of 805 injuries. Int Urogynecol J. 2014;25(12):1699-1706.

4. Adler AJ, Ronsmans C, Calvert C, Filippi V. Estimating the prevalence of obstetric fistula: a systematic review and meta-analysis. BMC Pregnancy Childbirth. 2013;13:246.
5. Tuncalp O, Tripathi V, Landry E, Stanton CK, Ahmed S. Measuring the incidence and prevalence of obstetric fistula: approaches, needs and recommendations. Bull World Health Organ. 2015;93(1):60-62.

6. National Bureau of Statistics of Tanzania, ICF Macro. Tanzania Demographic and Health Survey 2010. Dar es Salaam, Tanzania: NBC and ICF Macro; 2011.

7. Fiander AN, Vanneste T. TransportMYpatient: an initiative to overcome the barrier of transport costs for patients accessing treatment for obstetric fistulae and cleft lip in Tanzania. Trop Doct. 2012;42(2):77-79.

8. Bangser M. Obstetric fistula and stigma. Lancet. 2006;367(9509): 535-536.

9. Arrowsmith S, Hamlin EC, Wall LL. Obstructed labor injury complex: obstetric fistula formation and the multifaceted morbidity of maternal birth trauma in the developing world. Obstet Gynecol Surv. 1996;51(9): 568-574.

10. Siddle K, Mwambingu S, Malinga T, Fiander A. Psychosocial impact of obstetric fistula in women presenting for surgical care in Tanzania. Int Urogynecol J. 2013;24(7):1215-1220.

11. Wilson SM, Sikkema KJ, Watt MH, Masenga G. Psychological symptoms among obstetric fistula patients compared to gynecology outpatients in Tanzania. Int J Behav Med. 2015;22(5):605-613.

12. Gharoro EP, Agholor KN. Aspects of psychosocial problems of patients with vesico-vaginal fistula. J Obstet Gynaecol. 2009;29(7):644-647.

13. Mselle LT, Moland KM, Evjen-Olsen B, Mvungi A, Kohi TW. "I am nothing": experiences of loss among women suffering from severe birth injuries in Tanzania. BMC Womens Health. 2011;11:49.

14. Bangser M, Mehta M, Singer J, Daly C, Kamugumya C, Mwangomale A. Childbirth experiences of women with obstetric fistula in Tanzania and Uganda and their implications for fistula program development. Int Urogynecol J. 2011;22(1):91-98.

15. Browning A, Menber B. Women with obstetric fistula in Ethiopia: a 6-month follow up after surgical treatment. BJOG. 2008;115(12):1564-1569.

16. Yeakey M, Chipeta E, Rijken Y, Taulo F, Tsui A. Experiences with fistula repair surgery among women and families in Malawi. Glob Public Health. 2011;6(2):153-167.

17. Raassen TJ, Verdaasdonk EG, Vierhout ME. Prospective results after first-time surgery for obstetric fistulas in East African women. Int Urogynecol J Pelvic Floor Dysfunct. 2008;19(1):73-79.

18. Watt MH, Wilson SM, Sikkema KJ, et al. Development of an intervention to improve mental health for obstetric fistula patients in Tanzania. Eval Program Plann. 2015;50:1-9.

19. Hasson D, Arnetz B. Validation and findings comparing VAS vs. Likert scales for psychosocial measurements. Int Electron J Health Educ. 2005;8:178-192.

20. Sherbourne CD, Stewart AL. The MOS social support survey. Soc Sci Med. 1991;32(6):705-714.

21. Muhwava LS, Morojele N, London L. Psychosocial factors associated with early initiation and frequency of antenatal care (ANC) visits in a rural and urban setting in South Africa: a cross-sectional survey. BMC Pregnancy Childbirth. 2016;16:18.

22. Straus MA. Measuring intrafamily conflict and violence: the conflict tactics (CT) scales. J Marriage Fam. 1979;41(1):75-88.

23. Mahenge B, Likindikoki S, Stockl H, Mbwambo J. Intimate partner violence during pregnancy and associated mental health symptoms among pregnant women in Tanzania: a cross-sectional study. BJOG. 2013;120(8):940-946.

24. Herzog AR, Diokno AC, Brown MB, Normolle DP, Brock BM. Two-year incidence, remission, and change patterns of urinary incontinence in noninstitutionalized older adults. J Gerontol. 1990;45(2): M67-M74.

25. Rockwood TH, Church JM, Fleshman JW, et al. Patient and surgeon ranking of the severity of symptoms associated with fecal incontinence: the fecal incontinence severity index. Dis Colon Rectum. 1999; 42(12):1525-1532.

26. Radloff LS. The CES-D Scale: a self-report depression scale for research in the general population. Appl Psychol Meas. 1977;1(3): 385-401. 
27. Myer L, Smit J, Roux LL, Parker S, Stein DJ, Seedat S. Common mental disorders among HIV-infected individuals in South Africa: prevalence, predictors, and validation of brief psychiatric rating scales. AIDS Patient Care STDS. 2008;22(2):147-158.

28. Rosenberg M. Society and the Adolescent Self-Image. Princeton, N.J: Princeton University Press; 1965:xii-326.

29. Mlunde LB, Poudel KC, Sunguya BF, et al. A call for parental monitoring to improve condom use among secondary school students in Dar es Salaam, Tanzania. BMC Public Health. 2012;12:1061.

30. Balogun SK. A comparison of psychological status of vesico vaginal fistula (V. V. F.) sufferers and nonsufferers in southern Nigeria. IFE Psychologia. 1994;2(1):6-14.

31. Johnson KA, Turan JM, Hailemariam L, Mengsteab E, Jena D, Polan ML. The role of counseling for obstetric fistula patients: lessons learned from Eritrea. Patient Educ Couns. 2010;80(2):262-265.

32. Tashakkori A, Teddlie C. Handbook of Mixed Methods in Social \& Behavioral Research. Thousand Oaks, CA: Sage; 2003.
33. Miles MB, Huberman AM, Saldaña J. Fundamentals of Qualitative Data Analysis. 3rd ed. Thousand Oaks, CA: Sage; 2014.

34. Saldaña J. Writing Analytic Memos. The Coding Manual for Qualitative Researchers. Thousand Oaks, CA: Sage; 2012:41-57.

35. Lincoln YS, Guba EG. Naturalistic Inquiry. Newbury Park, CA: Sage Publications; 1985.

36. Shenton AK. Strategies for ensuring trustworthiness in qualitative research projects. Educ Inf. 2004;22:63-75.

37. Morrow SL. Quality and trustworthiness in qualitative research in counseling psychology. J Couns Psychol. 2005;52(2):250-260.

38. Weston K, Mutiso S, Mwangi JW, Qureshi Z, Beard J, Venkat P. Depression among women with obstetric fistula in Kenya. Int J Gynaecol Obstet. 2011;115(1):31-33.

39. Huebler F, Lu W. Adult and Youth Literacy: National, Regional and Global Trends, 1985-2015. Montreal, QC: UNESCO Institute for Statistics; 2013
International Journal of Women's Health

\section{Publish your work in this journal}

The International Journal of Women's Health is an international, peerreviewed open-access journal publishing original research, reports, editorials, reviews and commentaries on all aspects of women's healthcare including gynecology, obstetrics, and breast cancer. The manuscript management system is completely online and includes

\section{Dovepress}

a very quick and fair peer-review system, which is all easy to use. Visit http://www.dovepress.com/testimonials.php to read real quotes from published authors.

\footnotetext{
Submit your manuscript here: http://www.dovepress.com/international-journal-of-womens-health-journal
} 